\title{
A novel assessment and profiling of multidimensional apathy in
}

\author{
Alzheimer's disease \\ Ratko Radakovic ${ }^{12345^{*}}$, John M. Starr ${ }^{35}$ \& Sharon Abrahams ${ }^{1245}$ \\ ${ }^{1}$ Department of Psychology, University of Edinburgh, Edinburgh, UK \\ ${ }^{2}$ Anne Rowling Regenerative Neurology Clinic, University of Edinburgh, Edinburgh, UK \\ ${ }^{3}$ Alzheimer Scotland Dementia Research Centre, University of Edinburgh, Edinburgh, UK \\ ${ }^{4}$ Euan MacDonald Centre for MND Research, University of Edinburgh, Edinburgh, UK \\ ${ }^{5}$ Centre for Cognitive Ageing and Cognitive Epidemiology, University of Edinburgh, \\ Edinburgh, UK
}

Word Count: 4203

\footnotetext{
${ }^{*}$ Correspondence to: R. Radakovic, University of Edinburgh, Department of Psychology, 7 George Square, Edinburgh, UK, EH8 9JZ

Email addresses: r.radakovic@ed.ac.uk, radakovic.ratko@gmail.com Tel: +441316511303
} 


\begin{abstract}
Background: Apathy is a complex multidimensional syndrome, frequently reported in Alzheimer's disease (AD) and is associated with impaired awareness. Here we present a psychometrically robust method to profile apathy in AD. Objectives: To determine the validity and reliability of a multidimensional apathy measure, the Dimensional Apathy Scale (DAS), and explore the apathy subtype profile and its associations in AD. Methods: 102 people with AD and 55 healthy controls were recruited. Participants completed the DAS, the Apathy Evaluation Scale (AES), Geriatric Depression Short form (GDS-15) and Lawton Instrumental Activities of Daily Living (LIADL). Psychometric properties of the DAS were determined. AD-Control comparison was performed to explore group differences on the DAS. Latent Class Analysis (LCA) was used to explore the profile of apathy in AD. Results: The DAS had a good to excellent Cronbach's standardized alpha (self-rated $=0.85$, informant $/$ carer-rated $=0.93$ ), good convergent and divergent validity against standard apathy (AES) and depression (GDS-15) measures. Group comparison showed people with AD were significantly higher for all apathy subtypes than controls $(p<.001)$, and lacking in awareness over all apathy subtype deficits. LCA showed 3 distinct AD subgroups, with $42.2 \%$ in the Executive-Initiation apathy, 28.4\% in the Global apathy and $29.4 \%$ in the Minimal apathy group. Conclusions: The DAS is a psychometrically robust method of assessing multidimensional apathy in AD. The apathy profiles in $\mathrm{AD}$ are heterogeneous, with additional specific impairments relating to awareness dependent on apathy subtype.
\end{abstract}

Key Words: Apathy, Syndrome, Alzheimer disease, Psychometrics, Behavior Rating Scale, Awareness 


\section{Introduction}

Apathy, as a lack of motivation [1], is frequently reported as the most prominent behavioral syndrome in Alzheimer's disease (AD), and is associated with global disease severity and level of cognitive impairment $[2,3]$, and has a negative predictive role in clinical course [4]. Furthermore, it has been observed in predementia stages [5]. Apathy in $\mathrm{AD}$ is also associated with increased caregiver distress and burden [6] as well as functional decline [7] making it a negatively impactful behavioral symptom. There is also a pervasive association between increased apathy and anosognosia, or lack of awareness in AD [8]. Although apathy related anosognosia has been observed in earlier stages of the disease course $[9,10]$, it has also been suggested that this might be due to progression of neuropathology [7] with individuals later in the illness showing both symptoms. Mograbi and Morris [11] further reinforced this and proposed that apathy increases with lack of awareness of failures in cognitive tasks (error monitoring), while emotional reactions in response to experiences of illness or deficit (emotional reactivity), bearing similarity to awareness, remained relatively intact. They further dichotomized apathy against depression, in that the former is associated with more anosognosia.

However, previous research has shown some evidence that apathy is multidimensional e.g.. $[1,12]$, with the proposed diagnostic criteria of apathy recognizing the syndromatic nature of apathy $[13,14]$ but without a thorough measurement of specific subtypes [15]. This has been observed in dementia using traditional one-dimensional assessment tools such as the Neuropsychiatric Inventory (NPI) [16]. An example of this is that people with dementia who endorse more emotionally apathetic statements were more apathetic overall, and specifically showed more extreme and variable behavioral 
problems such as insensitivity and uncooperativeness [17]. A further study by Quaranta et al. [18] using the NPI found there to be differing apathy characteristics between AD and frontotemporal dementia, where the latter were reported to more frequently endorse statements relating to a lack of initiation, decreased emotional output and diminished interest towards friends or family. However, the NPI is a tool designed to assess apathy amongst other behavioral impairments and does not examine apathy multidimensionally. Similarly, the Apathy Evaluation scale (AES) [19] is a gold-standard one-dimensional measure for assessing apathy but is thought to be composed of 4 factors, called cognitive, behavioral, emotional and 'other', which have been used by previous research to calculate factorial subscores e.g. [20]. However, these factors are not consistently reported in other research, e.g. [21], and the AES has only been validated as a one-dimensional measure of apathy [15]. The Scale for Assessment for Negative Symptoms [22] is also less commonly used measure of different types of negative symptoms, affective blunting, avolition/apathy and social/emotional withdrawal, which have overlap with some apathy subtypes. More recently, Lille Apathy Rating Scale (LARS) has been validated in a group of mixed dementia patients [23] but measures uncorroborated factorial subscores of apathy.

At a neurobiological level, a perfusion imaging study using the Apathy Inventory (AI) [24], a simple multidimensional measure, observed that cognitive, behavioral and affective components of apathy were mediated by specific fronto-subcortical metabolic circuits [25]. Initiative aspects of apathy were negatively associated with right anterior cingulate cortex perfusion with emotional blunting aspects negatively associated with perfusion in right middle orbitofrontal gyrus in AD. Later structural imaging research, once more using the $\mathrm{AI}$, found that both in $\mathrm{AD}$ and Progressive Supranuclear Palsy there 
was distinct neuroanatomical basis for Initiative apathy relating to anterior cingulate cortex, and Emotional blunting aspects of apathy, relating to structural change insular cortex [26]. However, the AI was found not be a comprehensive or robust measure of multidimensional apathy [15].

Apathy is thought to be associated with prefrontal cortex-basal ganglia circuit dysfunction, manifesting as different subtypes of apathy, proposed in Levy and Dubois $[27,28]$ model. The Dimensional Apathy Scale (DAS) [29] has been designed to assess different apathy subtypes by a subscale-based, quantitative method that has been validated in amyotrophic lateral sclerosis [30] and Parkinson's disease [31]. The DAS measures lack of motivation for planning, attention and organization (Executive apathy), indifference or emotional neutrality (Emotional apathy) and self-generation of though (Initiation apathy). This Dimensional Apathy framework relates to different manifestation of demotivation, taking in to account both observable behavioral symptoms and cognitive deficits. While there are one-dimensional apathy tools that have been validated in $\mathrm{AD}$, there are limited comprehensive, validated tools assessing subtypes of apathy in this very common condition [15].

The primary aim of this study is to validate the DAS in a sample of people with AD and their carers. Furthermore, the profile of multidimensional apathy in AD was explored both through group comparison and latent profiling of AD based on the DAS, so as to determine subgroups based on the profile of scores across the three apathy subtypes. Finally, relevant links between the DAS, disease and functional variables will be explored. 


\section{Materials and Methods}

\section{Subjects}

People with AD and their carers were recruited through Join Dementia Research Platform and by the Health Information Centre (HIC) through the Scottish Dementia Research Interest Register (SDRIR), as described previously [32]. People with AD were approached through their carers to participate in the study. This was set up under the support of the Scottish Dementia Clinical Research Network (SDCRN) in 2008 to facilitate dementia research by providing access to suitable potential recruits in Scotland. Participants on the SDRIR were people referred by their clinicians, who have a diagnosis of dementia or a related cognitive disorder and have consented (or in cases where the person lacked capacity, through his/her legal representative). People with AD were diagnosed using the ICD-10 when joining the SDRIR [32] and those on Join Dementia Research Platform were diagnosed with the ICD-10 criteria aligned with NHS Scotland practice. Exclusion criteria for people with AD included those with Clinical Dementia Rating = 3 (due to severity of dementia), severe diabetes, epilepsy, alcohol/substance-related disorders, severe head injury (that required intensive care hospitalization), traumatic brain injury (inclusive of subarachnoid hemorrhage) and present or past other significant, comorbid medical illness (such as stroke, Parkinson's disease, psychiatric disease etc.). All people with AD that were recruited communitydwelling.

Additionally, healthy controls were recruited from the University of Edinburgh Volunteer Research Panel. They were prescreened before recruitment with the exclusion criteria of severe diabetes, epilepsy, alcohol/substance-related disorders, severe head injury (that required intensive care hospitalization), traumatic brain injury 
(inclusive of subarachnoid hemorrhage) and present or past other significant, comorbid medical illness (such as stroke, Parkinson's disease, psychiatric disease etc.). Controls were not specifically assessed for cognitive impairment in the present study, although were excluded if information on the University of Edinburgh Volunteer Research Panel database indicated cognitive impairment.

\section{Procedure and Assessments}

This was a postal questionnaire study where carers of people with AD were sent packs containing information sheets, consent forms and questionnaires regarding demotivation/apathy, mood and functional abilities of the person with AD. The carerrated pack asked the carers to complete the questionnaires based on their observations of the people with $\mathrm{AD}$ and the self-rated pack asked people with $\mathrm{AD}$ to self-rate their own demotivation/apathy and mood. Pre-paid, addressed envelopes were provided.

Both the carer-rated and self-rated packs contained the DAS $[29,30]$, Apathy Evaluation Scale (AES) [19] and the Geriatric Depression Scale-Short form (GDS-15) [33, 34] and the carers completed the Lawton Instrumental Activities of Daily Living (LIADL) [35]. The DAS is a 24-item scale that was used to measure multidimensional apathy. Executive, Emotional and Initiation apathy were assessed by subscales where each item was rated on a 4 point Likert scale, with the minimum score for each subscale being 0 (least apathy) and 24 (most apathy). The DAS total score ranges from 0 to 72 . DAS subscale impairment cutoffs were calculated on the basis of $\geq 2$ SD above the mean of the control sample. Parallel self- rated and informant/carer-rated versions were used. The AES was used as an 18-item, gold-standard measure of unidimensional apathy scored on a 4 point Likert scale, where 18 indicated least apathy and 72 indicated most 
apathy. Cutoffs of $>36.5$ for the self-rated and $>41.5$ for the carer-rated versions were used [21]. Furthermore, the AES is composed of a 4 factor substructure, Cognitive, Behavioral, Emotional and Other factors [19], where subfactorial scores can be calculated. Parallel self- rated and carer-rated versions were used. The GDS-15 is a 15item screen used to assess depression using a dichotomous scale, with scores ranging from 0 (not depressed) to 15 (most depressed). A clinical cut-off of $>6$ was used to indicate presence of depression [36]. Parallel self- rated and carer-rated versions were used. The LIADL is an 8-item carer-rated assessment of the functional independence of the person with $\mathrm{AD}$, with total scores ranging from 0 (low function, dependent) to 8 (high function, independent).

The Mini Mental State Exam (MMSE) [37] and the Addenbrooke's Cognitive Examination-Revised (ACE-R) [38] as measures of cognitive functioning were available from the Join Dementia Research Platform and SDRIR.

Ethical approval was obtained from the National Health Service (NHS) South East Scotland Research Ethics Committee 01 and the School Philosophy, Psychology and Language Sciences (PPLS), University of Edinburgh Ethical Committee, in accordance with the Declaration of Helsinki. Informed consent was obtained from all participants.

\section{Statistical analysis}

R and SPSS statistics V21.0 were used for analysis. Independent t-tests and Chi squared tests were used to compare demographics and clinical variables of the people with AD. Psychometric properties of the DAS were determined through Cronbach's Standardized alpha (internal consistency reliability) [39] and Holm corrected Pearson's correlations 
between DAS subscales and the AES (convergent validity) and GDS-15 (discriminant validity). A 3 x 3 mixed design ANOVA was used for comparison of Group (AD Informant/carer-rated vs AD Self-rated vs Control Self-rated) and DAS subscale (Emotional vs Executive vs Initiation), with post hoc Tukey's Honest Significant Differences (Tukey's HDS) tests. Holm corrected Pearson's correlations were used to examine clinical variable association with awareness discrepancy of people with AD on DAS apathy subscales. Apathy subtype awareness discrepancy was calculated through subtracting informant/carer-rated scores from self-rated scores.

Latent class analysis (LCA) was used to investigate clustering or classifying of people with AD based on the profile of informant/carer-rated scores on the DAS subscales using Mclust package in R [40]. Mclust is a model-based clustering, classification and density estimation software that is based on finite Gaussian mixture modelling. In Mclust, the optimal LCA model and number of clusters/classes are automatically selected according to Bayesian information criterion (BIC) [41]. Furthermore, the Integrated Classification Likelihood (ICL) criterion [42] was also applied to substantiate optimal model selection. A one-way MANOVA was used to confirm AD classes (subgroups) selected through LCA based on DAS subscales differences. Class subgroupings were classified based on their DAS scores and then compared on clinical and demographic variables using Chi squared tests and one-way ANOVAs (Holm corrected) with significant results followed up by post hoc Tukey's HDS tests.

\section{Results}

315 people with $\mathrm{AD}$ and their carers were recruited. There were a total of $102 \mathrm{AD}$ carers that returned the survey pack, with $17.6 \%$ being carers for people with early 
onset $\mathrm{AD}$ (below the age of 65 years old). The most common carer relationship to the person with $\mathrm{AD}$ was spouse. Of those, 55 people with $\mathrm{AD}$ returned their self-rated packs. 55 healthy controls were recruited. Table 1 shows AD and healthy control groups' clinical, demographic, apathy and depression characteristics.

\section{TABLE 1 HERE}

Table 1 shows that there was no significant difference between people with AD and controls on gender and years of education. However, while the AD group was significantly older than the control group, there was no significant age associated correlations between the AES and GDS-15, for both self- and carer-ratings. People with AD scored significantly higher on the AES and GDS-15 self-rated measures when compared to controls. $76.5 \%$ of people with AD scored above cut-off on the AES (carerrated) and 52.7\% of people with AD scored above cut-off on the GDS-15 (carer-rated).

For the $\mathrm{N}=55$ where both people with $\mathrm{AD}$ and their carers returned the packs, the AD informant/carer-ratings (mean $=46.6, \mathrm{SD}=9.9$ ) were significantly higher than AD selfratings $($ mean $=38.9, \mathrm{SD}=9.0)$ on the $\operatorname{AES}(t(108)=2.049, p<.001)$, with no significant difference on the GDS-15.

\section{Psychometric Properties of the DAS}

The DAS Cronbach's Standardized alpha value for the informant/carer-rated version was 0.93 and the self-rated version was 0.85 , which is excellent and good, respectively. At a DAS subscale level, Executive (informant/carer $=0.89$, self $=0.86$ ) and Initiation 
(informant $/$ carer $=0.88$, self $=0.84$ ) subscales were good. The informant $/$ carer-rated Emotional subscale was acceptable (0.73), self-rated version was questionable (0.54).

\section{TABLE 2 HERE}

Table 2 shows that DAS subscales correlated positively with the AES, with the self-rated Executive and Emotional correlating moderately and Initiation correlating strongly with the AES compared to the GDS-15. Supplementary Table 1 shows intercorrelations of DAS subscales and the 4 subfactorial scores of the AES.

\section{Alzheimer's disease apathy profiling Group Comparison}

\section{FIGURE 1 HERE}

Figure 1 shows the AD informant/carer-rated, AD self-rated and control self-rated group comparison on different DAS subscales. There was a significant main effect of Group $(F(1,489)=223.1, p<.001)$ and main effect of Subscale $(F(2,489)=40.0, p<$ .001). There was a significant Group and Subscale interaction $(F(2,489)=12.8, p<$ .001), which seemed to be driven by the difference between people with AD and controls on Executive and Initiation apathy, more so than Emotional apathy, as can be observed in Figure 1. Post hoc analysis showed that people with AD scored significantly higher on all subscales, both on self-rated (Executive: $p<.001$; Emotional: $p<.01$; Initiation: $p<.001$ ) and informant/carer-rated (Executive: $p<.001$; Emotional: $p<.001$; Initiation: $p<.001$ ), when compared to control self-ratings. AD informant/carer-ratings 
were found to be significantly higher than AD self-ratings informant/carers-ratings over all subscales indicative of a mean 3.4 point Executive $(p<.01), 1.7$ point Emotional $(p<$ $.05)$ and 2.9 Initiation $(p<.01)$ apathy subscale discrepancy in awareness.

Furthermore, when examining clinical variable associations, the DAS subscale scores (both self-rated and informant/carer-rated) were not significantly correlated with disease duration. Also, no significant correlations were observed between the discrepancy scores on any of the DAS subscales and disease duration.

\section{Latent Class Analysis}

\section{FIGURE 2 HERE}

For the LCA of informant/carer-ratings for AD, comparison of different models showed that a model "VVI" (diagonal, varying volume and shape) supporting a 3-class solution yielded a best fitting model with a BIC value of -710.2 . The second best model was "VVV" (ellipsoidal, varying volume, shape, and orientation) with 2-classes, presenting with a BIC value of -714.9 . This was a 4.7 point difference from the initial model, which was considered supportive of the 3-class "VVI" model [43]. The ICL criterion additionally supported 3-class solution "VVI" (diagonal, varying volume and shape) model with a ICL value of -721.9. A one-way MANOVA showed a significant difference the DAS subscales, supporting 3-class solution $(F(6,194)=53.1, p<.001$; Wilk's $\Lambda=0.1$, partial $\eta 2=.6)$. Figure 2 illustrates the DAS profiles of the different classes and Table 3 shows the DAS, demographic and clinical characteristics of the classes. 
Class 1 was the largest $(\mathrm{N}=43)$ and was characterized by displaying at least one apathy subtype. Table 3 shows higher scores on the Initiation and Executive apathy subscales. Also, using abnormality cutoffs, 58\% in this group were impaired on at least two apathy subscales, the most common of which was Executive and Initiation apathy, with only 37\% displaying global apathy over all DAS subscales and 5\% displaying one apathy subscale. This group was called the Executive and Initiation Apathy group. Class 2 was marginally the smallest group $(\mathrm{N}=29)$ but, unlike Class 1 , displayed distinctly most well defined characteristics, with highest mean scores over all apathy subscales.

Abnormality cutoffs showed 97\% displaying global apathy over all DAS subscales. This group was called the Global Apathy group. Class $3(\mathrm{~N}=30)$ was comparatively lower in mean scores on all apathy subscales, where $53 \%$ showing no apathy subscale impairment, with 30\% displaying one apathy subtype impairment and 17\% displaying multiple apathy subscale impairments, based on abnormality cutoffs. This was called the Minimal Apathy group.

\section{TABLE 3 HERE}

Table 3 shows confirmation of subgroup (class) differences based on DAS subscales and the AES showing a significant difference between the Executive and Initiation apathy, Global apathy and Minimal apathy groupings. The subgroups were also found to differ significantly on depression (GDS-15). Post hoc tests showed that the Minimal apathy group was significantly less depressed compared to the Executive and Initiation apathy subgroup $(p<.001)$ and the Global apathy subgroup $(p<.001)$. However no such difference was found between the Executive and Initiation apathy subgroup and the Global apathy subgroup. There were no other significant differences on other variables. 


\section{Discussion}

This study showed that the DAS is a valid and reliable instrument for detecting multidimensional apathy in AD, where the self- and informant/carer-rated versions had a good to excellent internal consistency reliability and good convergent validity against an existent gold-standard measure of apathy (AES). Specifically, Executive and Initiation apathy (both self- and informant/carer-rated versions) were found to be valid and reliable, whereas the self-rated Emotional apathy was less so. Though, self-rated DAS Emotional apathy was only significantly associated with the Emotional subfactorial score of the AES (Supplementary Table 1), showing a specific level of convergence within these domains and subscale-factor specific validity for the DAS Emotional apathy subscale. Nevertheless, the informant/carer-rated DAS was found to be more psychometrically robust, which is likely due to the well-documented lack of awareness of apathy associated with cognitive deficits in $\mathrm{AD}[8,24,44]$. This is also in concordance with more traditional instruments' reliance on external ratings, such as the NPI [16]. The discriminant validity was shown to be good, where Emotional apathy was not associated with depression, which supports the distinction between these two respective concepts of emotional neutrality and emotionality previously observed [30, 31].

Overall in the group comparison, Global apathy was observed in AD, both for selfratings and informant/carer-ratings, but at varying degrees. However, the difference between people with $\mathrm{AD}$ and controls self-ratings on Executive and Initiation subscales was found to be significant (6.6 points and 5.8 points, respectively), with Emotional apathy being much lower (2.2 points) but still significant. The LCA supported the 
presence of distinct profiles of apathy within $\mathrm{AD}$, showing subgroups of people with $\mathrm{AD}$ displaying Executive and Initiation apathy, Global apathy and Minimal apathy. The largest of these groups was the Executive and Initiation apathy subgroup $(\mathrm{N}=43)$, which was reinforced by people with $\mathrm{AD}$ and controls self-rating group comparison and magnitude of difference between the Executive and Initiation apathy subscales. As one of the most prominent behavioral symptoms in $\mathrm{AD}$, cognitive impairment is also associated with apathy [45-47]. While memory impairment is common in AD, attention [48] and executive dysfunction [49], such as planning, spatial navigation attention [5052] and verbal fluency [53] are also particularly noted to be impaired as the disease progresses to later stages, which is particularly relevant to our sample which is more impaired. However, it is important to differentiate between the DAS Executive apathy items and executive functioning assessments, wherein the overt, observational assessments of the former and the performance-based assessment of the latter, are unlikely to fully overlap but are more likely to measure similar elements relating to demotivation towards planning, organization and attention. Additionally, deficits of emotional processing, social awareness [54] and emotional decision-making [55] have also been observed in $\mathrm{AD}$, but may not be a defining deficit of the disease. More recent research using the LARS showed that people with AD showed less apathy in the "emotional" dimension and the "self-awareness" dimension when compared to people with behavioral variant frontotemporal dementia [56] and supports our findings of Emotional apathy as not a hallmark of AD. While the Dimensional Apathy framework attempts to incorporate observable behavioral and neuropsychological deficits, similar to Levy and Dubois $[27,28]$, how apathy subtypes map on to cognitive functioning is yet to be determined. This will give insight in to overlapping mechanisms of motivation and cognition. 
Further exploration showed that while awareness over all apathy subtypes, as assessed through a discrepancy of AD self-rating and informant/carer rating, was significantly impaired in AD, Executive and Initiation apathy was most impaired, while Emotional apathy was less impaired in magnitude. Anosognosia and apathy has been particularly related to executive dysfunction, where AD patients show a lack of awareness of errors in these tasks [11]. Furthermore, this type of error monitoring has been found to be associated with the anterior cingulate, an area implicitly associated with Levy and Dubois subtypes $[27,28]$. In addition, Mograbi and Morris suggest dissociation between impairment in awareness of their disease state and associated deficits, while emotional reactivity remaining intact in $\mathrm{AD}$. This is consistent with our findings in this study, where the difference observed between $\mathrm{AD}$ informant/carer-ratings and self-ratings on the Emotional apathy subscale were smaller than on the other subscales. We also found no significant difference on the standardized depression measure between AD self- and informant/carer-ratings, providing further support that emotional aspects of functioning, both neutral (apathy) and negative (depression) are not prone to the awareness deficits. In the scope of previous research, amyotrophic lateral sclerosis and Parkinson's disease [30, 31] have not shown apathy awareness deficits, which could suggest this is specific to dementia. Furthermore, this adds the construct of apathy subtype awareness to the emerging Dimensional Apathy framework that can be measured through discrepancy scores between self- and informant-carer ratings. Future research should aim to explore how this apathy subtype awareness deficit changes longitudinally over the course of the disease. 
Furthermore, both the Executive and Initiation apathy as well as the Global apathy subgroups, were observed to score higher on depression compared to the Minimal apathy subgroup. Due to the variable relationship of apathy and depression reported in literature there is a lack of consensus of the convergence of apathy and depression [5759]. It would therefore be beneficial to examine how apathy subtypes and depression converge, as well as diverge, throughout disease progression to further understand the complex relationship between these behaviors.

There are limitations to this study. Due to the nature of this postal questionnaire study, we were not able to utilize the proposed diagnostic criteria for apathy [14]. However, there is remit to apply these criteria in concordance with the DAS to refine apathy diagnosis. The discrepancy score between self-rated and informant/carer-rated DAS scores could be interpreted as anosognosia in people with $\mathrm{AD}$, it could also be due to the influence of caregiver burden associated with this disease, which has been shown to associate with apathy in AD [6]. Future research should explore how caregiver burden relates to different apathy subtypes. Furthermore, self-rating depression and apathy could affect reliability of reporting due to the severity of dementia. However, by including both self-rated and informant/carer-rated scales and instruments we hope to ameliorate the effects that could occur in relation to these two rating methods. A further limitation is that there was no formal assessment of cognitive impairment performed on the controls with only notes regarding this available for these participants, making it possible that some participants have mild cognitive impairment. Further research should look at how cognitive impairment associates with apathy subtypes both in patient populations and normative ageing, and determine the apathy subtype relationships with mild cognitive impairment. Additionally, there were no differences 
on medication status (cholinergic and glutaminergic) between apathy subgroups within AD, but other medication was not fully available for participants. However, studies looking at medication effects on apathy are sparse and report mixed results, with no studies looking directly at the effect on apathy subtypes [60]. Finally, while sample size $(\mathrm{AD}$ patient $=55$ and Carer $=102)$ of this study could be cited as a limitation, however previous studies validating and utilizing apathy measurement methods in dementia had similar or smaller sample sizes than our current study, examples include the LARS [23], NPI [16], AES [19] and AI [24]. However, use of the DAS in larger samples of dementia patients would further the understanding of multidimensional apathy in dementia.

In conclusion, the DAS was found to be psychometrically reliable and valid for measurement of multidimensional apathy in $\mathrm{AD}$. While both versions were informative, the informant/carer-rated version seemed slightly more psychometrically robust. While AD was characterized by a Global apathy over all subtypes, the heterogeneity of apathy based on subgrouping within AD was observed. A combination of Executive and Initiation apathy was shown to be central in $\mathrm{AD}$, which was further supplemented by an apathy subtype awareness deficit. Furthermore, in the scope of previous multidimensional apathy research in amyotrophic lateral sclerosis and Parkinson's disease $[30,31]$, these findings add to the complexities of apathy profiles and indicate a unique $\mathrm{AD}$ profile, further taking in to account apathy subtype awareness difficulties. This could prove clinically useful in distinguishing it from other neurodegenerative diseases, specifically other forms of dementia. Further research should investigate the degree of this apathy subtype awareness deficit while also determining the cognitive underpinnings of different types of apathy and pursuing further understanding of their impact on functional abilities, quality of life and caregiver burden. 


\section{Acknowledgments}

This research was funded by a scholarship from the Anne Rowling Regenerative Neurology Clinic, Alzheimer Scotland Dementia Research Centre and the University of Edinburgh. This work was supported by the Scottish Dementia Clinical Research Network who received funding from Scottish Ministers through the Chief Scientist Office. The views expressed in this publication are those of the authors and not necessarily those of Scottish Ministers or the Chief Scientist Office. We would like to express our gratitude to Mr Philip Brown (Deputy Network Manager, Scottish Neuroprogressive and Dementia Clinical Research Network) for his help with recruitment. We would like to thank the participants and their families for taking part in this research.

\section{Conflict of Interest/Disclosure Statement}

The authors have no conflict of interest to report.

\section{References:}

[1] Marin RS. (1991) Apathy: a neuropsychiatric syndrome. J Neuropsychiatry Clin Neurosci 3, 243-254.

[2] van Reekum R, Stuss DT, Ostrander L (2005) Apathy: why care? J Neuropsychiatry Clin Neurosci 17(1), 7-19.

[3] Chase TN (2011) Apathy in neuropsychiatric disease: diagnosis, pathophysiology and treatment. Neurotox Res 19, 266-278. 
[4] Stella F, Laks J, Govone JS, de Medeiros K, Forlenza OV (2015) Association of neuropsychiatric syndromes with global clinical deterioration in Alzheimer's disease patients. Int Psychogeriatr 28, 779-786.

[5] Apostolova LG, Cummings JL (2008) Neuropsychiatric manifestations in mild cognitive impairment: a systematic review of the literature. Dement Geriatr Cogn Disord $25,115-126$.

[6] Kaufer DI, Cummings JL, Christine D, Bray T, Castellon S, Masterman D, MacMillan D, Ketchel P, DeKosky ST (1998) Assessing the impact of neuropsychiatric symptoms in Alzheimer's disease: the Neuropsychiatric Inventory Caregiver Distress Scale. J Am Geriatr Soc 46(2), 210-215.

[7] Starkstein SE, Jorge R, Mizrahi R, Robinson RG (2006) A diagnostic formulation for anosognosia in Alzheimer's disease. J Neurol Neurosurg Psychiatry 77(6), 719-725.

[8] Starkstein SE, Brockman S, Bruce D, Petracca G (2010) Anosognosia is a significant predictor of apathy in Alzheimer's disease. J Neuropsychiatry Clin Neurosci 22(4), 378383.

[9] Spalletta G, Girardi P, Caltagirone C, Orfei MD (2012) Anosognosia and neuropsychiatric symptoms and disorders in mild Alzheimer disease and mild cognitive impairment. J Alzheimers Dis 29, 761-772.

[10] Aalten P, van Valen E, de Vugt ME, Lousberg R, Jolles J, Verhey FR (2006) Awareness and behavioral problems in dementia patients: a prospective study. Int Psychogeriatr 18, 3-17. 
[11] Mograbi DC, Morris RG (2014) On the relation among mood, apathy, and anosognosia in Alzheimer's disease. J Int Neuropsychol Soc 20(1), 2-7.

[12] Starkstein SE, Petracca G, Chemerinski E, Kremer J (2001) Syndromic validity of apathy in Alzheimer's disease. Am J Psychiatry 158, 872-877.

[13] Mulin E, Leone E, Dujardin K, Delliaux M, Leentjens A, Nobili F, Dessi B, Tible O, Agüera-Ortiz L, Osorio RS, Yassavage J, Dachevsky D, Verhey FRJ, Cruz Jentoft AJ, Blanc O, Llorca PM, Robert PH (2011) Diagnostic criteria for apathy in clinical practice. Int J Geriatr Psychiatry 26(2), 158-165.

[14] Robert PH, Onyike CU, Leentjens AFG, Dujardin K, Aalten P, Starkstein S, Verhey FRJ, Yassavage J, Clement JP, Drapier D, Bayle F, Benoit M, Boyer P, Lorca PM, Thibaut F, Gauthier S, Grossberg G, Vellas B, Byrne J (2009) Proposed diagnostic criteria for apathy in Alzheimer's disease and other neuropsychiatric disorders. Eur Psychiatry 24(2), 98104.

[15] Radakovic R, Harley C, Abrahams S, Starr JM (2015) A systematic review of the validity and reliability of apathy scales in neurodegenerative. Int Psychogeriatr 27, 903923.

[16] Cummings JL, Mega M, Gray K, Rosenberg-Thompson S, Carusi DA, Gornbein J (1994) The Neuropsychiatric Inventory comprehensive assessment of psychopathology in dementia. Neurology 44(12), 2308-2308. 
[17] Chow TW, Binns MA, Cummings JL, Lam I, Black SE, Miller BL, Freedman M, Stuss D, van Reekum R (2009) Apathy symptom profile and behavioral associations in frontotemporal dementia vs dementia of Alzheimer type. Arch Neurol 66(7), 888-893.

[18] Quaranta D, Marra C, Rossi C, Gainotti G, Masullo C (2012) Different Apathy Profile in Behavioral Variant of Frontotemporal Dementia and Alzheimer's Disease: A Preliminary Investigation. Current Gerontology and Geriatrics Research doi:10.1155/2012/719250

[19] Marin RS, Biedrzycki RC, Firinciogullari S (1991) Reliability and validity of the Apathy Evaluation Scale. Psychiatry Res 38(2), 143-162.

[20] Brodaty H, Altendorf A, Withall A, Sachdev P (2010) Do people become more apathetic as they grow older? A longitudinal study in healthy individuals. Int Psychogeriatr 22, 426-436.

[21] Clarke DE, Van Reekum R, Simard M, Streiner DL, Freedman M, Conn D (2007) Apathy in dementia: an examination of the psychometric properties of the Apathy Evaluation Scale. J Neuropsychiatry Clin Neuosci 19, 57-64.

[22] Reichman WE, Coyne AC, Amirneni S, Molino B, Egan S. (1996) Negative symptoms in Alzheimer's disease. Am J Psychiatry 153, 424-426.

[23] Fernández-Matarrubia M, Matías-Guiu JA, Moreno-Ramos T, Valles-Salgado M, Marcos-Dolado A, García-Ramos R, Matías-Guiu J (2016). Validation of the Lille’s Apathy Rating Scale in very mild to moderate dementia. Am J Geriatr Psychiatry 24, 517-527. 
[24] Robert PH, Clairet S, Benoit M, Koutaich J, Bertogliati C, Tible O, Caci H, Borg M, Brocker P, Bedoucha P (2002) The Apathy Inventory: assessment of apathy and awareness in Alzheimer's disease, Parkinson's disease and mild cognitive impairment. Int J Geriatr Psychiatry 17, 1099-1105.

[25] Benoit M, Clairet S, Koulibaly PM, Darcourt J, Robert PH (2004). Brain perfusion correlates of the apathy inventory dimensions of Alzheimer's disease. Int J Geriatr Psychiatry 19(9), 864-869.

[26] Stanton BR, Leigh PN, Howard RJ, Barker GJ, Brown RG (2013) Behavioural and emotional symptoms of apathy are associated with distinct patterns of brain atrophy in neurodegenerative disorders. J Neurol 260(10), 2481-2490.

[27] Levy R, Dubois B (2006) Apathy and the functional anatomy of the prefrontal cortex-basal ganglia circuits. Cereb Cortex 16(7), 916-928.

[28] Levy R (2012) Apathy: a pathology of goal-directed behaviour. A new concept of the clinic and pathophysiology of apathy. Rev Neurol (Paris) 168(8), 585-597.

[29] Radakovic R, Abrahams S (2014). Developing a new apathy measurement scale: Dimensional Apathy Scale. Psychiatry Res 219(3), 658-663.

[30] Radakovic R, Stephenson L, Colville S, Swingler R, Chandran S, Abrahams S (2016). Multidimensional apathy in ALS: validation of the Dimensional Apathy Scale.J Neurol Neurosurg Psychiatry 87, 663-669. 
[31] Radakovic R, Davenport R, Starr JM, Abrahams S (2017). Apathy dimensions in Parkinson's Disease. Int J Geriatr Psychiatry doi: 10.1002/gps.4697

[32] Law E, Connelly PJ, Randall E, McNeill C, Fox HC, Parra MA, Hudson J, Whyte LA, Johnstone J, Gray S, Starr JM (2013) Does the Addenbrooke's Cognitive Examinationrevised add to the Mini-Mental State Examination in established Alzheimer disease? Results from a national dementia research register. Int J Geriatr Psychiatry 28, 351-355.

[33] Yesavage JA, Sheikh JI (1986) Geriatric Depression Scale (GDS) Recent Evidence and Development of a Shorter Version. Clin Gerontol 5(1-2), 165-173.

[34] Brown LM, Schinka JA (2005) Development and initial validation of a 15- item informant version of the Geriatric Depression Scale. Int J Geriatr Psychiatry 20(10), 911918.

[35] Lawton MP, Brody EM (1969) Assessment of older people: Self- maintaining and instrumental activities of daily living. Gerontologist 9(3), 179-186.

[36] Wancata J, Alexandrowicz R, Marquart B, Weiss M, Friedrich F (2006) The criterion validity of the Geriatric Depression Scale: a systematic review. Acta Psychiatr Scand 114(6), 398-410.

[37] Folstein MF, Folstein SE, McHugh PR (1975) “Mini-mental state”. A practical method for grading the cognitive state of patients for the clinician. J Psychiatr Res 12, 189-198. 
[38] Mioshi E, Dawson K, Mitchell J, Arnold R, Hodges JR (2006) The Addenbrooke's cognitive examination revised (ACE-R): a brief cognitive test battery for dementia screening. Int J Geriatr Psychiatry 21, 1078-1085.

[39] Cronbach LJ (1951) Coefficient alpha and the internal structure of tests. Psychometrika 16(3), 297-334.

[40] Scrucca L, Fop M, Murphy TB, Raftery AE (2016) mclust 5: Clustering, classification and density estimation using gaussian finite mixture models. $R$ J 8(1), 289-317.

[41] Schwarz G (1978) Estimating the dimension of a model. Ann Stat 6(2), 461-464.

[42] Biernacki C, Celeux G, Govaert G (2000) Assessing a mixture model for clustering with the integrated completed likelihood. IEEE Trans Pattern Anal Mach Intell 22(7), 719-725.

[43] Raftery AE (1995) Bayesian model selection in social research. Sociological methodology 25, 111-163.

[44] Starkstein SE (2014) Anosognosia in Alzheimer's disease: Diagnosis, frequency, mechanism and clinical correlates. Cortex 61, 64-73.

[45] Robert PH, Berr C, Volteau M, Bertogliati C, Benoit M, Sarazin M, Largain S, Dubois B (2006) Apathy in patients with mild cognitive impairment and the risk of developing dementia of Alzheimer's disease: a one-year follow-up study. Clin Neurol Neurosurg 108(8), 733-736. 
[46] Palmer K, Di Iulio F, Varsi AE, Gianni W, Sancesario G, Caltagirone C, Spalletta G (2010) Neuropsychiatric predictors of progression from amnestic-mild cognitive impairment to Alzheimer's disease: the role of depression and apathy. J Alzheimers Dis 20(1), 175-183.

[47] Richard E, Schmand B, Eikelenboom P, Yang SC, Ligthart SA, Moll van Charante EP, van Gool WA, Alzheimer's Disease Neuroimaging Initiative (2012) Symptoms of apathy are associated with progression from mild cognitive impairment to Alzheimer's disease in non-depressed subjects. Dement Geriatr Cogn Disord 33(2-3), 204-209.

[48] Kolanowski AM, Fick DM, Yevchak MAM, Hill MNL, Mulhall MPM, McDowell MJA (2012) Pay attention!: The critical importance of assessing attention in older adults with dementia. J Gerontol Nurs 38(11), 23-27.

[49] Perry RJ, Hodges JR (1999) Attention and executive deficits in Alzheimer's disease. Brain 122(3), 383-404.

[50] McPherson S, Fairbanks L, Tiken S, Cummings JL, Back-madruga C (2002) Apathy and executive function in Alzheimer's disease. J Int Neuropsychol Soc 8(3), 373-381.

[51] Fernandez-Guinea S, Delgado ML, Frank A, García MR, Nieto S, Zaldunbide L, Oviedo D, Rivera P (2011) Planning abilities in aging, mild cognitive impairment and Alzheimer's disease patients. Alzheimers Dement 7(4), S243-S244.

[52] Tangen GG, Engedal K, Bergland A, Moger TA, Hansson O, Mengshoel AM (2015) Spatial navigation measured by the Floor Maze Test in patients with subjective 
cognitive impairment, mild cognitive impairment, and mild Alzheimer's disease. Int Psychogeriatr 27, 1401-1409.

[53] Bozeat S, Gregory CA, Ralph MAL, Hodges JR (2000) Which neuropsychiatric and behavioural features distinguish frontal and temporal variants of frontotemporal dementia from Alzheimer's disease? J Neurol Neurosurg Psychiatry 69(2), 178-186.

[54] Kumfor F, Sapey-Triomphe LA, Leyton CE, Burrell JR, Hodges JR, Piguet O (2014) Degradation of emotion processing ability in corticobasal syndrome and Alzheimer's disease. Brain 137(11), 3061-3072.

[55] Bayard S, Jacus JP, Raffard S, Gely-Nargeot, MC (2014) Apathy and Emotion-Based Decision-Making in Amnesic Mild Cognitive Impairment and Alzheimer's Disease. Behav Neurol doi: 10.1155/2014/231469

[56] Fernández-Matarrubia M, Matías-Guiu JA, Cabrera-Martín MN, Moreno-Ramos T, Valles-Salgado M, Carreras JL, Matías-Guiu J, (2017) Different apathy clinical profile and neural correlates in behavioral variant frontotemporal dementia and Alzheimer's disease. Int J Geriatr Psychiatry doi: 10.1002/gps.4695

[57] Landes AM, Sperry SD, Strauss ME, Geldmacher DS (2001) Apathy in Alzheimer's disease. J Am Geriatr Soc 49(12), 1700-1707.

[58] Tagariello P, Girardi P, Amore M (2009) Depression and apathy in dementia: same syndrome or different constructs? A critical review. Arch Gerontol Geriatr 49(2), 246249. 
[59] Mortby ME, Maercker A, Forstmeier S (2012) Apathy: a separate syndrome from depression in dementia? A critical review. Aging Clin Exp Res 24(4), 305-316.

[60] Harrison F, Aerts L, Brodaty H. (2016) Apathy in dementia: systematic review of recent evidence on pharmacological treatments. Curr Psychiatry Rep 18, 103. 
Table 1. Demographics, apathy and depression scores for AD, informant/carerrated $(\mathrm{N}=102)$, self-rated $(\mathrm{N}=55)$ and controls $(\mathrm{N}=55)$

\begin{tabular}{|c|c|c|c|c|}
\hline & $\begin{array}{l}\text { Informant/carer- } \\
\text { rated } A D \\
(\mathrm{~N}=102)\end{array}$ & $\begin{array}{l}\text { Self-rated } \\
A D \\
(\mathrm{~N}=55)\end{array}$ & $\begin{array}{l}\text { Control } \\
(\mathrm{N}=55)\end{array}$ & $\begin{array}{l}\text { Self-rated } \\
\text { AD vs } \\
\text { control } p \text { - } \\
\text { value }\end{array}$ \\
\hline Gender M/F & $52 / 50$ & $28 / 27$ & $28 / 27$ & 1.000 \\
\hline Age (mean, SD) & $78.2(8.5)$ & $77.5(7.9)$ & $\begin{array}{l}75.0 \\
(6.1)\end{array}$ & 0.036 \\
\hline Years of Education (mean, SD) & $13.2(3.7) \dagger \dagger$ & $\begin{array}{l}13.3 \\
(3.7) \dagger\end{array}$ & $\begin{array}{l}14.4 \\
(3.2)\end{array}$ & 0.060 \\
\hline AES & $51.7(11.5)$ & $38.9(9.0)$ & $\begin{array}{l}28.8 \\
(5.2)\end{array}$ & $<.001$ \\
\hline GDS-15 & $7.3(4.4)$ & $5.1(4.0)$ & $\begin{array}{l}1.9 \\
(2.1)\end{array}$ & $<.001$ \\
\hline LIADL Score (mean, SD) & $3.0(2.2)$ & & & \\
\hline Age of onset (mean, SD) years & $74.6(8.2)+\dagger \dagger$ & & & \\
\hline $\begin{array}{l}\text { Disease duration (mean, SD) } \\
\text { years }\end{array}$ & $3.9(2.4) \dagger+\dagger$ & & & \\
\hline Medication (Cholinergic/ & $78.4 \% / 4.9 \% /$ & & & \\
\hline Glutaminergic/ Both/ None/ & $2.9 \% / 10.8 \% /$ & & & \\
\hline Unavailable \%) & $2.9 \%$ & & & \\
\hline CDR (0.5/ 1/ 2/ Unavailable & $43.1 \% / 39.2 \% /$ & & & \\
\hline$\%)$ & $14.7 \% / 2.9 \%$ & & & \\
\hline MMSE score (mean, SD) & $22.0(5.3) \dagger+\uparrow \dagger$ & & & \\
\hline ACE-R score (mean, SD) & $63.3(18.1)+\uparrow+\uparrow$ & & & \\
\hline
\end{tabular}

Significant values in bold. AD=Alzheimer's Disease; SD=standard deviation; AES=Apathy Evaluation Scale; GDS-15=Geriatric Depression Scale-Short form; LIADL=Lawton Instrumental Activities of Daily Living; CDR= Clinical Dementia Rating; MMSE= Mini-Mental State Exam; ACER=Addenbrooke's Cognitive Examination- Revised $\dagger \mathbf{N}=\mathbf{3 9}$

$\dagger \dagger \mathrm{N}=\mathbf{4 2}$

$\dagger+\uparrow \mathbf{N}=90$

†††† $\mathbf{N}=\mathbf{8 0}$ 
Table 2. Informant/carer-rated DAS and self-rated DAS subscale correlations compared to standardized apathy (AES) and depression (GDS-15) measures

\begin{tabular}{lll}
\hline Informant/carer $(\mathrm{N}=102)$ & AES & GDS-15 \\
\hline DAS Executive subscale & $\mathbf{0 . 8 0 * * *}$ & $\mathbf{0 . 4 9} * * *$ \\
DAS Emotional subscale & $\mathbf{0 . 6 7 * * *}$ & $\mathbf{0 . 3 0 * *}$ \\
DAS Initiation subscale & $\mathbf{0 . 8 6 * * *}$ & $\mathbf{0 . 4 8} * * *$ \\
DAS Total & $\mathbf{0 . 7 5} * * *$ & $\mathbf{0 . 3 6} * * *$ \\
\hline Self (N=55) & AES & GDS-15 \\
\hline DAS Executive subscale & $\mathbf{0 . 5 8 * * *}$ & $\mathbf{0 . 5 3} * * *$ \\
DAS Emotional subscale & $\mathbf{0 . 3 7 *}$ & 0.13 \\
DAS Initiation subscale & $\mathbf{0 . 6 7 * * *}$ & $\mathbf{0 . 4 2 * *}$ \\
DAS Total & $\mathbf{0 . 7 5 * * *}$ & $\mathbf{0 . 5 2} * * *$
\end{tabular}

Significant values in bold. DAS=Dimensional Apathy Scale; AES=Apathy Evaluation Scale; GDS15=Geriatric Depression Scale- Short Form $p<.001^{* * *}, p<.01^{* *}, p<.05^{*}$ 
Table 3. AD Class comparison on DAS subscales, descriptive and clinical variables (informant/carer-rated $\mathrm{N}=102$ )

\begin{tabular}{|c|c|c|c|c|}
\hline & $\begin{array}{l}\text { Executive and } \\
\text { Initiation Apathy } \\
\text { (Class 1) }\end{array}$ & $\begin{array}{l}\text { Global Apathy } \\
\text { (Class 2) }\end{array}$ & $\begin{array}{l}\text { Minimal } \\
\text { Apathy (Class } \\
\text { 3) }\end{array}$ & $\begin{array}{l}p \text { - } \\
\text { value }\end{array}$ \\
\hline \multicolumn{5}{|l|}{ DAS Subscale } \\
\hline Executive (mean, SD) & $17.2(3.2)$ & $21.9(1.5)$ & $10.6(4.4)$ & $<.001$ \\
\hline Emotional (mean, SD) & $14.6(3.2)$ & $18.9(2.6)$ & $10.6(4.0)$ & .002 \\
\hline Initiation (mean, SD) & $21.1(1.5)$ & $23.8(0.4)$ & $14.6(3.2)$ & $<.001$ \\
\hline \multicolumn{5}{|c|}{$\begin{array}{l}\text { Descriptive and } \\
\text { Clinical }\end{array}$} \\
\hline $\mathrm{N}$ (male \%) & $43(46.5 \%)$ & $29(44.8 \%)$ & $30(63.3 \%)$ & 1.000 \\
\hline Onset (Early/Late) & $8 / 35$ & $4 / 25$ & $6 / 24$ & 1.000 \\
\hline Age (mean, SD) & $78.9(8.8)$ & $79.2(7.3)$ & $76.2(8.9)$ & 1.000 \\
\hline $\begin{array}{r}\text { Years of Education } \\
\text { (mean, SD) }\end{array}$ & $12.7(3.9) \dagger$ & $14.0(2.9) \dagger \dagger$ & $13.5(3.7)+\uparrow+$ & 1.000 \\
\hline AES (mean, SD) & $53.2(4.8)$ & $63.9(4.2)$ & $37.2(6.0)$ & $<.001$ \\
\hline GDS-15 (mean, SD) & $8.0(4.1)$ & $9.4(4.0)$ & $4.3(3.5)$ & .007 \\
\hline $\begin{array}{r}\text { LIADL Score (mean, } \\
\text { SD) }\end{array}$ & $3.0(2.0)$ & $1.3(1.4)$ & $4.4(2,1)$ & .268 \\
\hline $\begin{array}{r}\text { Age of onset (mean, } \\
\text { SD) years }\end{array}$ & $75.4(8.5) \neq$ & $74.3(7.2) \neq \ddagger$ & $73.8(8.9)$ 㧊 & 1.000 \\
\hline $\begin{array}{l}\text { Disease duration } \\
\text { (mean, SD) years }\end{array}$ & $4.0(2.3) \neq$ & $4.7(2.2)$ 㧊 & $3.1(2.3)$ 㧊 & 1.000 \\
\hline $\begin{array}{r}\text { Medication } \\
\text { (Cholinergic/ } \\
\text { Glutaminergic/ Both/ } \\
\text { None/ Unavailable \%) }\end{array}$ & $\begin{array}{l}79.1 \% / 7.0 \% / 0 \% / \\
14.0 \% / 0 \%\end{array}$ & $\begin{array}{l}72.4 \% / 3.4 \% / \\
6.9 \% / 13.8 \% / \\
3.4 \%\end{array}$ & $\begin{array}{l}83.3 \% / 3.3 \% / \\
3.3 \% / 6.7 \% / \\
3.3 \%\end{array}$ & 1.000 \\
\hline $\begin{array}{r}\text { MMSE score (mean, } \\
\text { SD) }\end{array}$ & $22.3(5.4) \Delta \Delta$ & $\begin{array}{l}19.9(5.3) \\
\text { キキキキ }\end{array}$ & $24.5(3.9) \Delta$ & 1.000 \\
\hline $\begin{array}{r}\text { ACE-R score (mean, } \\
\text { SD) }\end{array}$ & 64.7 (17.1) $\Delta \Delta \Delta$ & $\begin{array}{l}56.4(17.9) \\
\text { キキキキ }\end{array}$ & $72.6(16.7) \neq$ & 1.000 \\
\hline 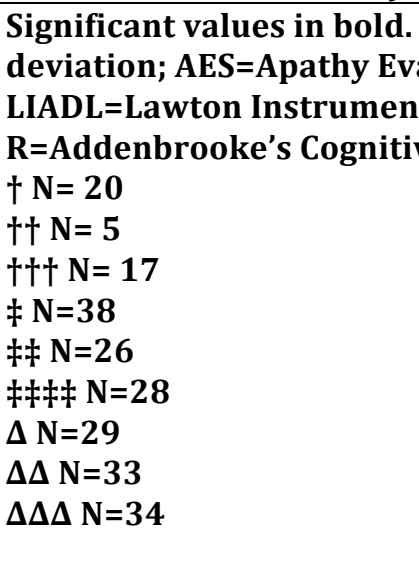 & $\begin{array}{l}\mathrm{AD}=\text { Alzheimer's Diseas } \\
\text { luation Scale; GDS-15= } \\
\text { al Activities of Daily Liv } \\
\text { e Examination- Revised }\end{array}$ & $\begin{array}{l}\text { DAS=Dimensiona } \\
\text { eriatric Depressio } \\
\text { ng; MMSE = Mini-N }\end{array}$ & $\begin{array}{l}\text { Apathy Scale; } \mathbf{S D}= \\
\text { Scale-Short form } \\
\text { ental State Exam; }\end{array}$ & andard \\
\hline
\end{tabular}




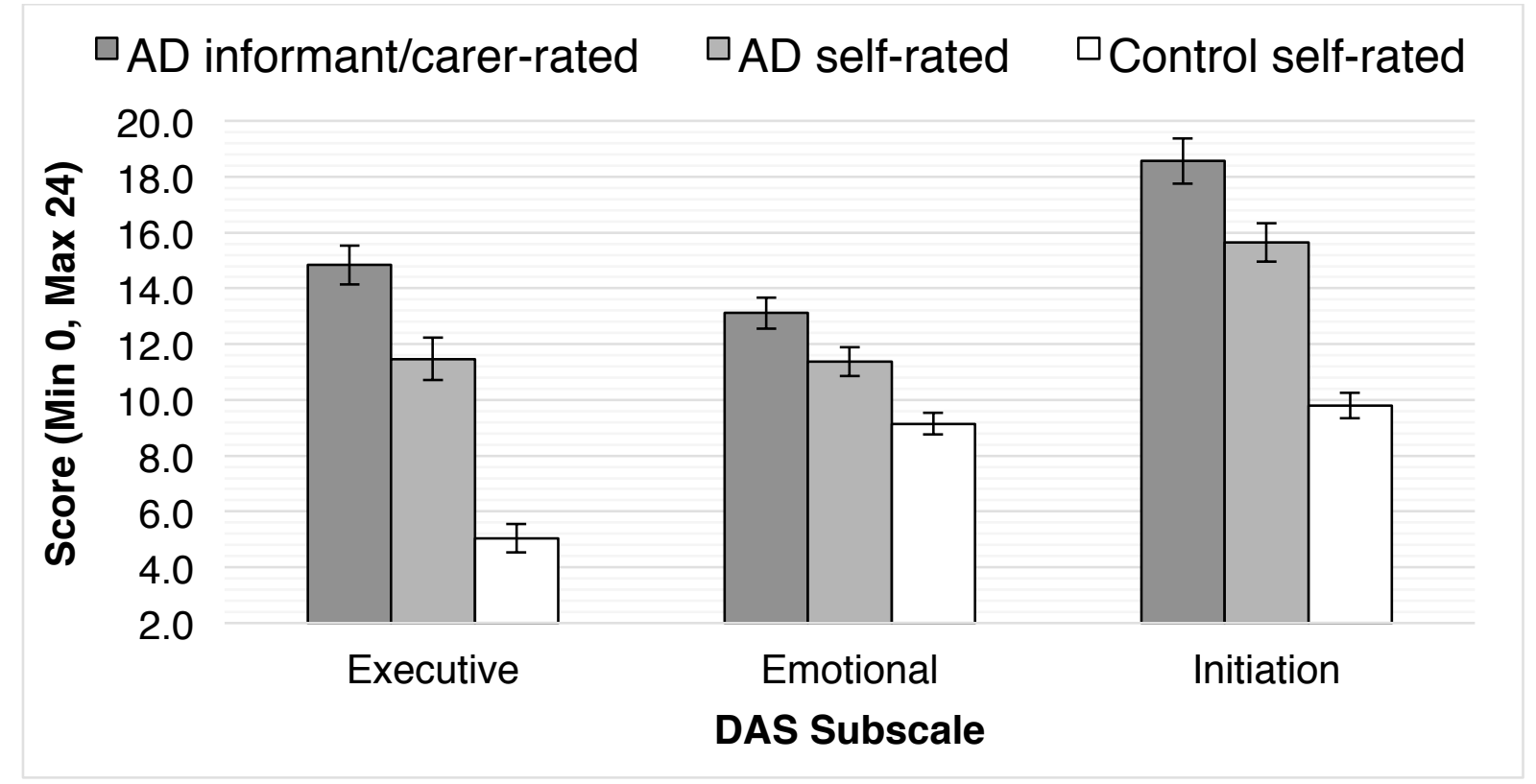

Figure 1. Comparison of AD informant/carer-rated $(N=55), A D$ self-rated $(N=55)$ and Control self-rated $(\mathrm{N}=55)$ groups on DAS subscales 


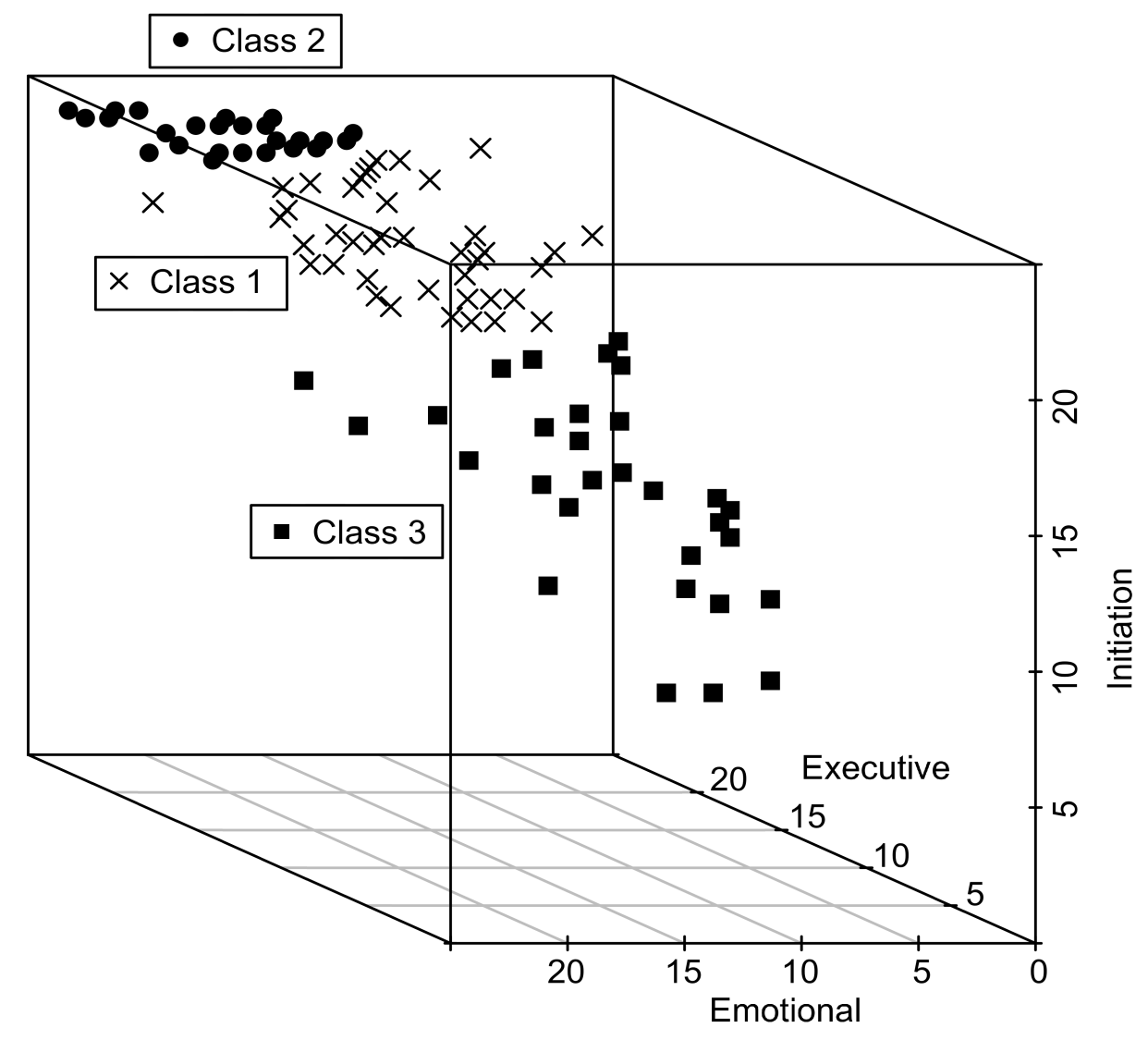

Figure 2. AD (Informant/carer-rated; $\mathrm{N}=102$ ) subgroupings (Classes) based on LCA of DAS Emotional ( $x$ axis), DAS Initiation ( $y$ axis) and DAS Executive ( $z$ axis) subscale scores. 
Supplementary Table 1. Informant/carer-rated DAS and self-rated DAS subscale correlations compared to 4 factors of the AES

\begin{tabular}{lllll}
\hline Informant/carer (N=102) & $\begin{array}{l}\text { AES Cognitive } \\
\text { Factor }\end{array}$ & $\begin{array}{l}\text { AES Behavior } \\
\text { Factor }\end{array}$ & $\begin{array}{l}\text { AES Emotional } \\
\text { Factor }\end{array}$ & $\begin{array}{l}\text { AES Other } \\
\text { Factor }\end{array}$ \\
\hline DAS Executive subscale & $\mathbf{0 . 7 6 * * *}$ & $\mathbf{0 . 7 7 * * *}$ & $\mathbf{0 . 4 9 * * *}$ & $\mathbf{0 . 7 4 * * *}$ \\
DAS Emotional subscale & $\mathbf{0 . 6 6 * * *}$ & $\mathbf{0 . 6 0 * * *}$ & $\mathbf{0 . 5 6 * * *}$ & $\mathbf{0 . 6 9} * * *$ \\
DAS Initiation subscale & $\mathbf{0 . 8 3 * * *}$ & $\mathbf{0 . 7 6 * * *}$ & $\mathbf{0 . 6 8 * * *}$ & $\mathbf{0 . 7 8 * * *}$ \\
\hline Self (N=55) & AES Cognitive & AES Behavior & AES Emotional & AES Other \\
& Factor & Factor & Factor & Factor \\
\hline DAS Executive subscale & $\mathbf{0 . 5 0 * *}$ & $\mathbf{0 . 4 8 * *}$ & 0.24 & $\mathbf{0 . 5 3 * * *}$ \\
DAS Emotional subscale & 0.30 & 0.23 & $\mathbf{0 . 4 6 * *}$ & 0.28 \\
DAS Initiation subscale & $\mathbf{0 . 5 6 * * *}$ & $\mathbf{0 . 6 4 * * *}$ & $\mathbf{0 . 3 8 *}$ & $\mathbf{0 . 5 5 * * *}$ \\
\hline
\end{tabular}

Significant values in bold. DAS=Dimensional Apathy Scale; AES=Apathy Evaluation Scale; GDS15=Geriatric Depression Scale- Short Form $p<.001^{* * *}, p<.01^{* *}, p<.05^{*}$ 